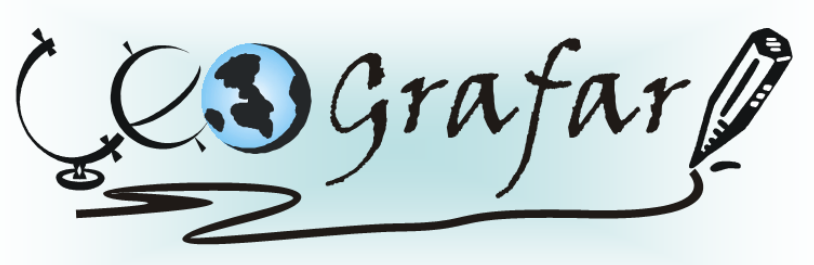

Revista Eletrônica do Programa de Pós-Graduação em Geografia - UFPR

\title{
REDES E TERRITÓRIOS NA AMAZÔNIA: \\ O estudo geográfico das estratégias territoriais das empresas de telefonia móvel no Estado do Pará1
}

\author{
JOSÉ QUEIROZ DE MIRANDA NETO²
}

\begin{abstract}
Resumo: Neste trabalho investigamos as territorialidades das empresas de telefonia móvel celular que operam no Estado do Pará (Vivo, Tim, Amazônia Celular e Oi). Para atingir esse objetivo, fazemos uso de um caminho teórico que aborda duas categorias analíticas: a rede e o território, que são permeados por outros dois conceitos derivados: a territorialidade e o que denominamos circuitos de poder. Utilizamos como corpus os dados obtidos junto as operadoras de telefonia móvel e os dados oficiais da Agência Nacional de Telecomunicações (ANATEL), com destaque ao cadastro nacional de Estações Radiobase (ANATEL, 2007). A metodologia utilizada consiste no levantamento de dados secundários, seguido da elaboração de mapas, gráficos e quadros com base no estado do Pará. Esses instrumentos são analisados com intuito de definir o cenário da competição, os circuitos de poder e as áreas privilegiadas. Verificamos que as empresas de telefonia móvel utilizam o território como segmento de mercado, equiparando o cidadão à figura do consumidor. As operadoras selecionam suas áreas de atuação através de critérios eminentemente econômicos, privilegiando as áreas de maior atrativo para a acumulação da capitais.
\end{abstract}

Palavras Chave: Empresas de Telefonia Celular; Estado do Pará; Redes; Território; Competitividade; Estratégia.

\section{NETS AND TERRITORIES IN AMAZÔNIA The geographical study of the territorial strategies of the mobile telephony companies in Pará's State}

\begin{abstract}
In this work, we investigated the territorialities of the cell phone telephone mobile companies that operate in the State of Pará. These companies are Vivo, Tim, Amazônia Celular and Oi. In pursuing this purpose, we traced a theoretical routs that deals with two categories of analysis: the network and the territory, both marked by two other derived concepts: the territoriality and what we call circuits of power. Our corpus is composed by some information collected in the cell phone telephone mobile companies placed in Pará and the official data from Agência Nacional de Telecomunicações (ANATEL), more specifically, the national list of Radiobase Stations (2007). The methodology that we adopt consists of the collect of secondary data as well as the elaboration of maps, graphs and tables based on the reality of Pará State. These factors are analyzed in order to define the scene of the competition, the circuits of power and the privileged areas. We verified that the cell phone telephone mobile companies use the territory as a market segment, placing the citizen in the same status of a consumer. The companies select its areas of performance based on economic criteria, privileging the areas of higher attractive for the accumulation of the capitals.
\end{abstract}

\footnotetext{
${ }^{1}$ Este artigo foi produzido com base na dissertação de mestrado "Redes, Território e Competitividade: a estratégia das empresas de telefonia móvel celular no Estado do Pará" avaliada pelo Programa de Pós Graduação em Geografia do Instituto de Filosofia e Ciências Humanas - UFPa.

2 Mestre em Geografia pelo Programa de Pós-graduação em Geografia da UFPa, na área de concentração Gestão Urbana e Regional. geonetoufpa@yahoo.com.br
} 
Key-words: Cell Phone Telephone Mobile Company; State of Pará; Network; Territory; Competitiveness; Strategy.

\section{INTRODUÇÃO}

Esse artigo é, em parte, resultado de um esforço que fazemos há algum tempo e remete a tentativa de entender como novas territorialidades convivem e conflitam no mundo contemporâneo através da formulação de "redes estratégicas", gerando "circuitos de poder". Nesses circuitos, cada território é, por um lado, a condição para existência do outro e, por outro lado, reinam as lógicas privativas e egoístas segundo as regras excludentes da competitividade. Neste estudo priorizamos a atuação das empresas de telefonia móvel no estado do Pará, que constituem conformações territoriais reticulares, móveis e, por vezes, superpostas a outras formas de ação.

A primeira parte do trabalho propõe uma conciliação entre redes e territórios, que esbarra na problemática fundamental entre a materialidade e as ações conduzidas pelos sujeitos sociais. Nesse aspecto, dois objetivos pretendemos atingir em primeira instância, primeiro fazer uma formulação teórica que nos permita entender o território como realidade inseparável dos fluxos que a ele dão sentido e conteúdo e, depois, comprender como os territórios poder ser construídos através do controle/apropriação dos fluxos que trafegam por intermédio das redes, dando base para múltiplas formas de territorialidade.

A segunda parte apresenta alguns dados sobre a atuação das empresas de telefonia no territórios paraense, explicando como a mobilização de diversos agentes políticos e econômicos formam uma verdadeira rede estratégica para operacionalização de metas comuns de cunho técnico. As empresas de telefonia móvel celular necessitam compartilhar suas ações com o poder público, com as empresas de telefonia fixa e com empresas de telefonia móvel e, noutro plano, necessitam selecionar áreas para sua própria atuação, ponderando critérios competitivos que abrangem estratégias espaciais (definindo clientes prioritários, áreas com potencial, nichos preferenciais e zonas marginais) muitas vezes em oposição aos interesses dos demais seguimentos do circuito (a exemplo do proprio interesse público). 


\section{REDES E TERRITÓRIOS: UMA APROXIMAÇÃO}

A rede possui uma polissemia que enriquece o conjunto de significações agregadas ao conceito e permite uma rica análise epistemológica. Segundo Santos (1996, p. 209), não obstante as definições do termo sejam múltiplas, pode-se admitir que se enquadram em duas grande matizes: "a que considera o seu aspecto, a sua realidade material, e a outra, onde é também levado em conta o dado social". Podese afirmar, com clareza, que essas definições estão presentes como essência em quase todas as construções teóricas relacionadas à rede, como veremos mais adiante.

O cientista social Pierre Musso faz algumas incursões teóricas em torno de muitas das significações da "rede" e procura impetrar um "corte metodológico" das várias concepções e metáforas atribuídas ao termo. $\mathrm{O}$ autor começa sua análise pelo que chama "visão biometafísica da rede" (metáfora do tecido), na qual a rede é concebida como um ajuntamento de linhas amarradas em sua extremidade, formando malhas através da conexão entre linhas e nós. Uma outra visão muito mais abrangente e ideologicamente arquitetada do conceito de rede é aquela que provém das definições políticas Diderot, que permite analisar o social e o político a partir da fusão entre a rede e o corpo. Nesse sentido, a visão biopolítica da rede simboliza, no iluminismo, "a ambivalência do controle e da circulação" (MUSSO, 2001, p. 202), aspecto que podemos retomar geograficamente através de uma análise territorial.

O debate entre redes e territórios, no entanto, constitui uma trilha teórica na qual muitos autores têm percorrido em tom de dicotomia, isto é, enquanto realidades opostas, desconectadas, que coexistem mais que não se completam. Esse princípio dualista é compartilhado pelo sociólogo Bertrand Badie, ao desenvolver seu raciocino sobre o "fim dos territórios" (BADIE, 1995), onde afirma que o mundo das redes opõe duas maneiras distintas de articulação dos indivíduos e dos grupos. A primeira é definida numa perspectiva mais zonal, introvertida, relacionada ao enraizamento estável baseado nos laços políticos construídos pelos cidadãos. A segunda é mais extrovertida, baseada em fidelidades móveis, instáveis, desenraizadas, articulada por meio de fluxos que rompem limites. 
Essa vertente dualista, que é ainda partilhada por muitos outros autores, traz um grande problema teórico-metodológico quando associada aos estudos geográficos que, por vezes, se deparam com o caráter imprescindível da mobilidade, absolutamente pertinente ao espaço. Essa primeira oposição é norteada por outra, a saber, aquela que não consegue determinar um ponto de encontro entre a materialidade e as ações, gerando uma ambigüidade entre os elementos que estão arraigados no território e as ações que, pela sua fluidez, transcenderiam qualquer domínio material. Nossa proposta é fugir dessa visão essencialmente dicotômica e inserir uma outra, na qual nem as redes sejam tão "virtualizadas" nem os territórios sejam tão "enraizados".

Milton Santos utiliza um conceito que propõe entender o espaço a partir da mobilidade, como um conjunto indissociável de sistemas de objetos e sistemas de ações: "o espaço é hoje um sistema de objetos cada vez mais artificiais, povoados por sistemas de ações igualmente imbuídos de artificialidade, e cada vez mais tendentes a fins estranhos, ao lugar e a seus habitantes. (Santos, 1998. p. 90). Um estudo atual da rede estaria relacionado, portanto, a idade dos objetos (a idade mundial da técnica) e de sua longevidade (a idade local do objeto), da distribuição desses objetos e seu uso pela sociedade. Nesse sentido, uma visão atual das redes supõe "um estudo estatístico das quantidades e das qualidades técnicas mas, também, a avaliação das relações que os elementos da rede mantém com a presente vida social, em todos os seus aspectos, isto é, essa qualidade de servir como suporte corpóreo do cotidiano" (SANTOS, 1996, p. 210). O autor insiste no aspecto da técnica porque, para ele, embora "animadas por fluxos, que dominam o seu imaginário, as redes não prescindem de fixos - que constituem sua base técnica - mesmo quando esses fixos são pontos".

Claude Raffestin define o sistema territorial em tessitura (limites), nós (pontos que simbolizam a posição dos atores) e redes (sistema de linhas que desenham tramas), que chamou de "invariantes territoriais". As redes assegurariam o controle do espaço e o controle no espaço através de uma função circulação-comunicação, onde, quer se trate de uma coisa ou de outra, os atores estariam sempre diante de uma trama que designa os caminhos que, articulados aos nós, projetam suas ações e determinam o "desenho" de sua territorialidade. Assim como Milton Santos, 
Raffestin não ignorou o aspecto social da rede ao considerar que "é conveniente, pois, decifrar a rede por meio de sua história e do território na qual estão instaladas, por meio dos modos de produção que permitem a sua instalação e das técnicas que Ihe deram forma" (RAFFESTIN, 1993, p. 208). Sintetizando, a rede é um é "instrumento" pelo qual se torna possível a projeção do poder por parte de um determinado ator sintagmático (ator que realiza um programa), daí ela ser "um instrumento por excelência do poder". Percebe-se, a partir dessas considerações, que tanto Raffestin quanto Milton Santos entendem a rede enquanto realidade totalmente intrínseca ao território, definindo-a enquanto "materialidade" (técnica) e "instrumento" (suporte de ações) no território, ou seja, a rede é entendida como "elemento" ou como "fortalecedora" de determinado território.

Sobre o aspecto da materialidade das redes, Haesbaert (2004, p. 292) afirma que "nunca iremos encontrar, a não ser num nível metafórico, redes completamente 'desterritorializadas' no sentido de sua total imaterialidade". Podemos citar dois exemplos para justificar essa afirmação, primeiro as redes técnicas de satélite que, embora não possuam ligações materiais, jamais podem prescindir dos fixos geradores dos sinais eletromagnéticos, constituindo, tecnicamente, redes formadas apenas de pontos. O segundo exemplo é o das chamadas "comunidades virtuais" que, embora constituam redes sociais a priori desmaterializadas, devem ser sustentadas por redes técnicas (computador, provedor, modem, linhas de conexão, etc.) que tornam sua existência possível. Ao se deter nas múltiplas perspectivas do território, o autor deixa claro que o território não pode ser definido como enraizamento e limite, ao contrário de Raffestin, e afirma que "territorializar-se significa também, hoje, construir e/ou controlar fluxos/redes e criar referenciais simbólicos num espaço em movimento, no e pelo movimento" (HAESBAERT, 2004, p. 280).

Sobre as relações de poder e de exclusão inerentes à rede, Dias (1995) sintetiza alguns de nossos argumentos iniciais, a saber, o poder de conexidade, de solidariedade e também de exclusão, aspetos que tentamos recuperar ao longo de nosso texto tomando o território enquanto categoria de análise. Segundo Dias (1995, p. 5): 
Os fluxos, de todo tipo - das mercadorias às informações pressupõe a existência de redes. A primeira propriedade das redes é a conexidade qualidade de conexo -, que tem ou em que há conexão, ligação. Os nós das redes são, assim, lugares de conexões, lugares de poder e de referência, como sugere Raffestin. É antes de tudo pela conexidade que a rede solidariza os elementos. Mas ao mesmo tempo em que tem o potencial de solidarizar, de conectar, também tem de excluir. Os organismos de gestão da rede, quer se trate de gestão técnica, econômica e jurídica não são neutros, eles colocam em jogo relações sociais entre os elementos digamos, solidarizados, e aqueles que permanecem marginalizados.

Diante do emaranhado de conceitos expostos acima, cabe desenvolvermos como últimos argumentos dessa seção, além do que já foi explicitado pelos autores acima, algumas definições no sentido de aproximar o entendimento das redes enquanto realidade inseparável do território e vice versa. Para tanto tomaremos alguns argumentos fundamentais, a saber:

(i) A rede não deve ser tomada simplesmente como "um conjunto de linhas e pontos" (tal como na geometria euclidiana), mas enquanto "relações" que se dão no tempo e no espaço de forma descontínua, ou seja, sem preenchê-los por completo. Com esta definição podemos atenuar os impasses causados pelas redes técnicas do tipo hetzerianas (redes de satélite, de telefonia celular, etc.) que podem prescindir das linhas (físicas) sem, contudo, se livrar das conexões.

(ii) Nenhuma rede é destituída de materialidade, assim como nenhuma materialidade é desprovida de seu aspecto social (apropriação política e/ou simbólica), nesse caso, as redes são concomitantemente sociotécnicas (produto da sociedade em determinado momento histórico) e técnico-políticas (expressão das relações de poder/dominação). Deste modo, toda rede social (ou "territorial", nos termos de Dupuy) depende, de uma forma ou de outra, de um meio material que the sirva de conduto, assim como toda rede técnica depende de um meio social que the dê significado.

(iii) "Redes técnicas" (como de transporte, energia e telecomunicações), podem também ser definidas como "redes territoriais" quando tomadas no âmbito da estruturação de territórios tanto no caso específico dos limites de um país, de uma província, de um estado, de um município quanto na própria territorialidade de uma empresa ou de um grupo de atores sociais. 
(iv) Os territórios podem se comportar ora como zonas ora como redes ou ainda podem conter as duas realidades simultaneamente. Diacronicamente, 0 território pode passar de "mais enraizado" para "mais reticulado" ou, sincronicamente, dependendo da escala de observação, podemos visualizar mais o seu aspecto zonal ou mais o seu aspecto reticular.

\section{EMPRESAS DE TELEFONIA NA AMAZÔNIA: TERRITORIALIDADES E CIRCUITOS DE PODER}

No contexto amazônico, o estado do Pará têm sido um dos mais permeáveis quanto à introdução de inovações e o estabelecimento de redes técnicas. Tais inovações, ao contrário do que propõe alguns teóricos, não são introduzidas ao acaso, mas estão situados em uma base social bem mais ampla, cujas intenções perpassam os limites da mera materialidade. O que propomos é que a estratégia do estabelecimento de redes é resultado de uma mobilização de diversos atores, uma co-relação de forças que pode gerar "surtos de solidariedade" no tocante a operacionalização de projetos de base espacial. Trata-se, portanto, de múltiplas territorialidades numa dialética entre a cooperação e o conflito, que chamaremos de "circuitos de poder". Como afirma Vieira e Vieira (2003, p. 118) os círculos de poder atuam num sistema de forças que representam interesses comuns, mas com percepções distintas da realidade. "Isso produz posições divergentes quanto ao modo de gestão do território, principalmente em relação à prática estratégica para realizar um objetivo econômico, de um lado, e de outro, o interesse público". Tratamse, portanto, de solidariedades organizacionais que se tornaram muito mais evidentes em função da nova configuração do estado, potencializadas pela quebra de monopólios estatais.

As vias fluviais representaram durante muito tempo os principais meios para a comunicação entre os habitantes da bacia do rio Amazonas. Contudo, "a partir do momento em que o movimento social exige suas mudanças técnicas, novas necessidades são criadas, operando substituições na hora adequada" (SANTOS, 1996). A necessidade de um novo sistema técnico se instala, efetivamente, na Amazônia a partir do comércio gerado pela exportação da borracha, intensificando a 
circulação de pessoas e de produtos e caracterizando um novo modo-de-vida, marcado por construções urbanas e inovações técnicas importantes. Uma primeira resposta a essas novas necessidades se deu em 13 de outubro de 1886, com a inauguração da estação Telegráfica de Belém do Pará, integrando a Amazônia aos centros nacionais e mundiais via telégrafo eletrônico.

O telefone, contemporâneo do sistema de telégrafos por muito tempo, teve suas primeiras unidades introduzidas na Amazônia entre 1890 e 1917, com a utilização das redes telegráficas existentes, sendo Belém do Pará a primeira cidade a utilizar-se do sistema. Nesse ritmo, até 1968 poucas cidades possuíam centrais telefônicas e terminais telefônicos em serviço no território paraense, como demonstrado no quadro abaixo:

QUADRO 01 - PARÁ: CENTRAIS TELEFÔNICAS E TERMINAIS - 1968

\begin{tabular}{|l|c|c|}
\hline Município & $\begin{array}{c}\text { Centrais } \\
\text { Telefônicas }\end{array}$ & $\begin{array}{c}\text { Terminais } \\
\text { Telefônicos }\end{array}$ \\
\hline ALENQUER & 1 & 200 \\
\hline BELÉM & 3 & 6.000 \\
\hline BRAGANÇA & 1 & 200 \\
\hline CASTANHAL & 1 & 200 \\
\hline JACUNDÁ & - & 1 \\
\hline ÓBIDOS & 1 & 100 \\
\hline SANTARÉM & 1 & 401 \\
\hline TUCURUÍ & 1 & 4 \\
\hline TOTAL & 9 & 7.106 \\
\hline
\end{tabular}

Fonte: Empresas Telefônicas, 1968. IBGE - Brasil.

$\mathrm{Na}$ época, o serviço era prestado por 7 empresas de telefonia locais, correspondendo a um total de 9 centrais e 7.106 terminais presentes no território paraense até 1968. Estes números, entretanto, eram pouco significantes frente as 616 centrais e os 501.382 terminais presentes no estado de São Paulo, revelando desde já a estrema desigualdade presente no território brasileiro quanto a esse serviço. 
QUADRO 02 - EMPRESAS TELEFÔNICAS - DATA DE FUNDAÇÃO E NÚMERO DE TERMINAIS (1968)

\begin{tabular}{|l|c|c|}
\hline \multicolumn{1}{|c|}{ Empresa } & $\begin{array}{c}\text { Data de } \\
\text { Fundação }\end{array}$ & $\begin{array}{c}\text { №. de } \\
\text { Terminais }\end{array}$ \\
\hline Empresa telefônica de Santarém LTDA & 1954 & 101 \\
\hline Companhia Telefônica de Bragança & 1957 & 200 \\
\hline Telefônica da Estrada de Ferro Tocantins & 1959 & 6 \\
\hline Empresa Telefônica Castanhalense LTDA & 1961 & 231 \\
\hline Empresa Telefônica de Obidos S.A & 1962 & 101 \\
\hline Companhia Telefônica de Alenquer & 1966 & 170 \\
\hline Companhia Telefônica do Município de Belém (COTEMBEL). & 1966 & 10.264 \\
\hline
\end{tabular}

Fonte: Empresas Telefônicas, 1972. IBGE - Brasil.

No final do anos 60 e início da década de 70, sob a égide do Governo Militar, verifica-se uma simplificação institucional dos serviços devido a criação da Companhia de Telecomunicações do Pará (COTELPA), em 1967, definindo a atuação de apenas duas companhias: a COTELPA, com 20.689 terminais e a Telefônica da Estrada de Ferro Tocantins, que atuava às proximidades de Tucuruí com apenas 6 terminais. Redefinindo os números da telefonia fixa neste período, temos então:

QUADRO 03 - PARÁ: CENTRAIS TELEFÔNICAS E TERMINAIS - 1972

\begin{tabular}{|l|l|l|}
\hline Município & $\begin{array}{l}\text { Centrais } \\
\text { Telefônicas }\end{array}$ & $\begin{array}{l}\text { Terminais } \\
\text { Telefônicos }\end{array}$ \\
\hline Abaetetuba & 1 & 400 \\
\hline Alenquer & 1 & 140 \\
\hline Belém & 3 & 20.000 \\
\hline Bragança & 1 & 400 \\
\hline Cametá & 1 & 140 \\
\hline Capanema & 1 & 200 \\
\hline Castanhal & 1 & 230 \\
\hline Marabá & 1 & 400 \\
\hline Monte Alegre & 1 & 140 \\
\hline Óbidos & 1 & 100 \\
\hline Salinópolis & 1 & 200 \\
\hline Santa Izabel & 1 & 200 \\
\hline Soure & 1 & 600 \\
\hline Tucuruí & 1 & 180 \\
\hline Vigia & 1 & 200 \\
\hline Total & 18 & 23.546 \\
\hline
\end{tabular}

Fonte: Empresas Telefônicas, 1972. IBGE - Brasil.

A lei $n \div$. 6.896, de 19 de Junho de 1972 determina autorização para que se processe a fusão entre a Companhia Telefônica do Município de Belém (Cotembel) 
e a Companhia Telefônica do Pará (Cotelpa) formando uma nova empresa de economia mista. Surgindo assim, neste mesmo ano, Companhia de Telecomunicações do Pará S.A. (TELEPASA), que em 1973 tomou a atual denominação de TELEPARÁ, estando submetida ao contido na Lei ํo 6.404, de 15.12.76. A empresa representa a orientação estatal da política econômica brasileira definida neste período, com a criação do sistema Telebrás em julho deste mesmo ano. Em 1976 o sistema de telefonia já contava com 16 municípios, um total de 18 centrais telefônicas e 34.897 acessos, conforme descrito no quadro abaixo.

QUADRO 04 - PARÁ: CENTRAIS TELEFÔNICAS E TERMINAIS - 1976
\begin{tabular}{|l|c|c|}
\hline \multicolumn{1}{|c|}{ Município } & $\begin{array}{c}\text { Centrais } \\
\text { Telefônicas }\end{array}$ & $\begin{array}{c}\text { Terminais } \\
\text { Telefônicos }\end{array}$ \\
\hline Abaetetuba & 1 & 390 \\
\hline Alenquer & 1 & 190 \\
\hline Belém & 3 & 30.907 \\
\hline Bragança & 1 & 380 \\
\hline Cametá & 1 & 140 \\
\hline Capanema & 1 & 220 \\
\hline Castanhal & 1 & 220 \\
\hline Marabá & 1 & 390 \\
\hline Monte Alegre & 1 & 150 \\
\hline Óbidos & 1 & 100 \\
\hline Paragominas & 1 & 299 \\
\hline Salinópolis & 1 & 380 \\
\hline Santa Izabel & 1 & 190 \\
\hline Santarém & 1 & 610 \\
\hline Soure & 1 & 150 \\
\hline Vigia & 1 & 190 \\
\hline Total & 18 & 34.897 \\
\hline
\end{tabular}

Fonte: Empresas Telefônicas, 1968. IBGE - Brasil.

A Telepará surgiu num momento em que o Estado brasileiro ensejou dinamizar sua atividade empresarial, objetivando estar presente em áreas complementares às empresas originalmente criadas, assim surgiram nas décadas de 60 e 70 , os grandes grupos da Eletrobrás-1961 (holding do sistema federal de eletricidade); Sidebrás; Nuclebrás; Portobrás; Telebrás (Holding do Sistema de Telecomunicações). A Telepará seria, então, uma das empresas que iriam compor o novo Sistema de Telecomunicações do território brasileiro, tendo como área de concessão os limites políticos do Estado do Pará. Até o final da década de 60, contudo, o Pará sequer possuía equipamentos para o serviço de comunicação interurbana. Foi somente na década de 70 , através do sistema de comunicação em 
microondas $^{3}$, que foi possível quebrar 0 isolamento desse Estado em relação ao Brasil e o mundo. Em 1972, através da atuação da Embratel, tivemos um sistema de comunicação interurbana funcionado no estado do Pará com 35 circuitos e 5.824 km de extensão, e em 1976 este número passa para 114 circuitos e mais $4.344 \mathrm{~km}$ de extensão.

Segundo Becker (2001) as redes de telecomunicações constituem uma malha de grande importância tanto para articulação da Amazônia aos grandes centros mundiais do capitalismo, quanto para a própria integração entre os sujeitos sociais presentes na região. Segundo a autora "ao se expandirem e sustentarem as riquezas circulante, financeira e informacional, as redes se socializam. E essa socialização está gerando movimentos sociais importantes, os quais também tendem a se transnacionalizarem (BECKER, 2005, p. 71).

De forma recorrente, a autora se utiliza dos argumentos de Lefebvre (1991) ao evidenciar a existência de uma malha de duplo controle: técnico e político. Nos argumentos de Becker (2001)

impõe sobre o território uma malha de duplo controle - técnico e político constituída de todos os tipos de conexões e redes, capaz de controlar fluxos e estoques, e tendo as cidades como base logística para a ação. Essa malha, que denominamos "malha programada", foi implantada entre 196585, no estado brasileiro da Amazônia, visando completar a apropriação física e o controle do território (BECKER, 2001, p. 137).

No caso específico das telecomunicações, podemos afirmar que a malha de controle político esteve atribuída ao grande papel normativo do Estado brasileiro entre as décadas de 60 e 80 no que diz respeito às telecomunicações. A criação do Contel, da Telebrás e da Embratel são exemplos desse esforço. Quanto à malha de controle técnico, podemos citar o grande aparato tecnológico baseado na comunicação via satélite, que permitiu articulações locais/ nacionais, bem como locais/ globais, tornando mais eficiente a conectividade regional.

\footnotetext{
${ }^{3}$ Sistema de transmissão interurbana, em alta freqüência (VHF) através de antenas parabólicas, sem uso de fio, ocupando número determinado de canais ou circuito. Cada canal ou circuito completa uma chamada telefônica. O número de circuitos é o número de canais ligados à mesa em condições de ser utilizado. (IBGE, 1978).
} 
A modernização conservadora do Governo Militar, alicerçada no monopólio estatal, começa a refletir suas contradições na década de 80 , evidenciando uma série de problemas que se alastram nas décadas seguintes. Nesta época, "os investimentos nas empresas de telecomunicações caem, os serviço se degradam, a demanda por telefone é muito maior que a oferta, os preços são impraticáveis e os prazos não são cumpridos" (GALINA, 2003. p. 98). Diante desse contexto desfavorável à ingerência estatal, iniciam-se nos primeiros anos da década de 90 as discussões políticas sobre o processo de privatização do setor de telefonia e, no plano global, começam a ser costuradas as estratégias entre as "gigantes" do ramo (Portugual Telecom, MCI WordCom, IBM) ${ }^{4}$.

A reestruturação do setor vai acontecer a partir de 1995, com a quebra do monopólio estatal, e se define nos anos subseqüentes com a venda das operadoras estatais (1998). A Telebrás é, então, dividida em três grandes Holdings, das quais a Tele Norte-leste (que em 1999 passa a se chamar Telemar S.A.) recebe os direitos para execução dos serviços da Telecomunicações do Pará S.A (Telepará). Em fevereiro de 1999 a Vésper S.A. entra como empresa espelho na região I, utilizando uma solução inovadora no mercado de telefonia fixa residencial: um sistema de acesso fixo sem fio, baseado na tecnologia CDMA, na freqüência de $1,9 \mathrm{GHz}$. A Agência Nacional de Telecomunicações (ANATEL), criada em agosto de 1997, tem como papel fundamental uma ação contraditória, pois ao mesmo tempo em que introduz a competição na exploração dos serviços de telecomunicações, tenta promover a universalização do acesso aos serviços básicos.

A partir dessa reestruturação, os números da telefonia passam a evoluir exponencialmente tanto no território nacional, quanto no Estado do Pará. No caso deste último, os números saltam de 189.700 acessos fixos instalados em 1994, para 442.763 em 1999, crescendo 3,4 vezes. Os números da telefonia celular, no entanto, são bem mais surpreendentes, passando de 4.200 acessos em 1994 para 152.200 em 1999, crescendo mais de 36 vezes.

\footnotetext{
${ }^{4}$ Walter Tadahiro Shima estuda as chamadas "alianças estratégicas" entre as empresas do setor de telefonia no Brasil, afirmando que "se pode deduzir que a nova organização técnica da rede, que inclui padrões digitais, é aplicada a organização institucional entre as operadoras. Por outro lado, a forma de organização técnica da rede é aplicada à organização de uma rede econômica" (SHIMA, 2004, p. 8).
} 
No caso específico das regiões menos dinâmicas quanto à alocação de objetos técnicos ao espaço, a exemplo da Amazônia, o sistema celular tem funcionado como uma alternativa à falta de infraestruturas para a telefonia fixa, que demanda mais investimentos. Esse, contudo, é um problema antigo da região, e diz respeito não apenas à telefonia fixa, mas a outros sistemas que dependem de um cabeamento estruturado, como é o caso do sistema de energia elétrica. Dentre os fatores que inviabilizam grandes investimentos desse tipo no interior da Amazônia podemos citar: a) a realidade dispersa de algumas localidades, no interior de grandes fazendas, ao longo dos rios ou em meio à floresta; b) a intricada malha fluvial, que dificulta a instalação e a manutenção de postes, transformadores, subestações, centrais, troncos de fibras ópticas etc.; c) o impacto ambiental das trilhas florestais, necessitando de autorização dos órgãos competentes e d) o reduzido interesse do poder público em promover a instalação de equipamentos urbanos em cidades do interior, principalmente naquelas que são menos atrativas aos investimentos externos. No caso da telefonia, a adoção do sistema de comunicação em radio microondas foi uma das primeiras soluções encontradas para quebrar o isolamento da região.

Com a modernização e a difusão em larga escala da telefonia celular, essa tecnologia foi rapidamente absorvida por diversas cidades do interior e se tornou um dos principais sistemas de comunicação da região. As Estações Radiobase (ERB) ${ }^{5}$ passaram, rapidamente, a compor a nova paisagem das cidades amazônicas e a simbolizar uma nova dinâmica, em que a comunicação à distância é o elemento chave.

Nesse sentido, tanto o número de estações de rádio quanto as áreas de cobertura tendem a aumentar consideravelmente nesta região nos próximos anos. Verificamos, no Estado, até novembro de 2007, 688 ERB's, destas 275 encontramse no município de Belém e 46 em Ananindeua (ver mapa 01), que são as unidades mais bem servidas no estado, tanto em relação à área de cobertura quanto à presença de concessionárias em atuação. Somando os números da Região Metropolitana de Belém (RMB) ${ }^{6}$, são mais de 355 estações, correspondendo a 51\%

\footnotetext{
${ }^{5}$ Estação Rádio Base (ERB) ou "Cell site" é a denominação dada em um sistema de telefonia celular para a Estação Fixa com que os terminais móveis se comunicam.

${ }^{6}$ Foram somados os municípios de Belém, Ananindeua, Marituba e Barcarena.
} 
do total. Fazendo uma relação entre número de estações radiobase e a população do Estado, pode-se atingir uma densidade total de 10.335 habitantes por ERB, sendo que no município de Belém esse número cai quase à metade (5.194), na RMB sobe para 6.055. No resto do território, excetuando somente os 4 municípios da RMB, têm-se 13.775 por ERB, ou seja, a alta concentração de ERB na RMB não se justifica pelo fato de haver um maior contingente populacional nessa área, uma vez que a densidade obtida é 2,65 vezes maior que a densidade do restante do território e 1,94 vezes maior que a densidade de todo Estado do Pará.

MAPA 01: MAPA DE ESTAÇÕES RADIOBASE NO ESTADO DO PARÁ - 2007

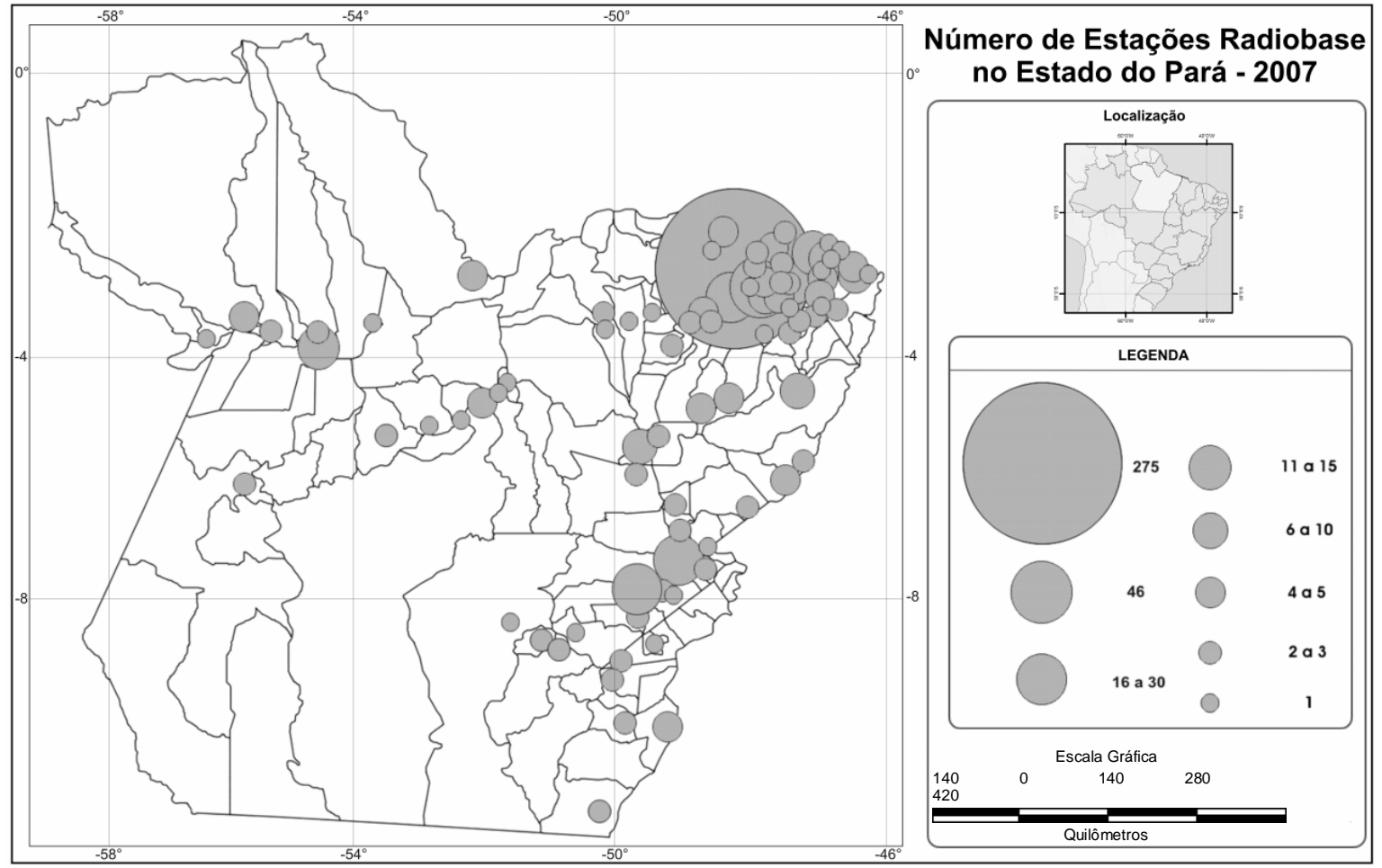

Fontes: Fontes: Base Cartográfica Integrada Digital do Brasil ao Milionésimo. Rio de Janeiro. IBGE, 2003. Cadastro de Estações Radiobase da Agência nacional de Telecomunicações (ANATEL), 2007.

Até o final de 2007, dos 143 municípios do Pará, apenas 94 dispõem do serviço de telefonia móvel (65,7\%) (ANATEL, 2007). Contudo, em menos de 7 anos houve um crescimento de mais de 27 vezes o número de municípios abrangidos, demonstrando o ritmo pelo qual a iniciativa privada pretende seguir com esses números nos próximos anos. 
O número de estações radiobase entre as concessionárias de telefonia móvel no Estado do Pará revela o domínio da TIM Celular S.A, uma das últimas empresas a adentrar nesse setor, com 195 ERBs instaladas, superando os anos de domínio da Amazônia Celular S/A, do grupo Tele Norte Participações, que vem em segundo com 189 ERBs. A OI, da Tele Norte-leste participações, aparece ao lado da VIVO, ambas com 152 ERB's.

O número de localidades atendidas por cada operadora constitui, no entanto, um dado bem mais complexo, visto que os municípios não são abrangidos em sua totalidade pelo sistema celular, que é limitado ao número de ERB's, à capacidade dos transmissores e à tecnologia adotada. Alguns municípios, por exemplo, possuem cobertura apenas na área da sede, outros são atendidos em localidades bem mais afastadas devido alguns fatores relevantes, tais como: áreas rurais com considerável contingente populacional; localidades de atividade socioeconômica intensa (garimpos, fazendas, áreas agrícolas); área de projetos econômicos importantes; vilas planejadas; localidades turísticas; sede de grandes firmas. Os dados sobre as operadoras, tecnologias, áreas de cobertura e outros indicativos podem, então, ser definidos pelo quadro abaixo.

QUADRO 05 - DADOS SOBRE AS OPERADORAS DE TELEFONIA MÓVEL NO ESTADO DO PARÁ

\begin{tabular}{|l|l|c|c|}
\hline \multicolumn{1}{|c|}{ EMPRESA } & \multicolumn{1}{c|}{ TECNOLOGIA } & MUNICÍPIOS & $\begin{array}{c}\text { \% } \\
\text { POPULAÇÃO }\end{array}$ \\
\hline VIVO & TDMA/CDMA & 81 & 81,77 \\
\hline Amazônia Celular & TDMA/GSM & 63 & 75,44 \\
\hline TIM & GSM & 56 & 73,50 \\
\hline OI & GSM & 26 & 53,23 \\
\hline
\end{tabular}

Fonte: Operadoras de Celular e TELECO (2007).

O cenário da competitividade revela que as empresas adotam diferentes estratégias que estão relacionadas, sobretudo, à capacidade técnico-financeira das mesmas e ao tempo em que ambas se instalam no território. Dependendo dessa relação, as empresas se apresentam de forma concentrada ou dispersa. Podem, também, privilegiar certas regiões de maior interesse econômico, como as áreas metropolitanas. Em nosso estudo, inserimos alguns dados de market share ${ }^{7}$ das

\footnotetext{
${ }^{7}$ Nesse caso, é calculada a quantidade de celulares e adições líquidas das operadoras de celular no Estado do Pará, por DDD.
} 
empresas de telefonia celular (gráfico 01), ou seja, o cálculo que designa a fatia de marcado detida por essas operadoras. Além disso, utilizamos também números referentes ao total de municípios abrangidos e a estimativa de atendimento à população.

Os dados revelam que o domínio da VIVO acontece somente nas regiões sudeste e oeste do Pará, enquanto que no Nordeste a TIM consegue absorver a maior parcela do mercado, porém com menor atendimento à população $(77,5 \%)$ que a Amazônia Celular (81,8\%). Sabe-se, contudo, que a maioria da população do Estado está concentrada no Nordeste Paraense, que é onde se verifica uma maior disputa entre as empresas, sendo a diferença percentual entre as concessionárias de no máximo $12 \%$.

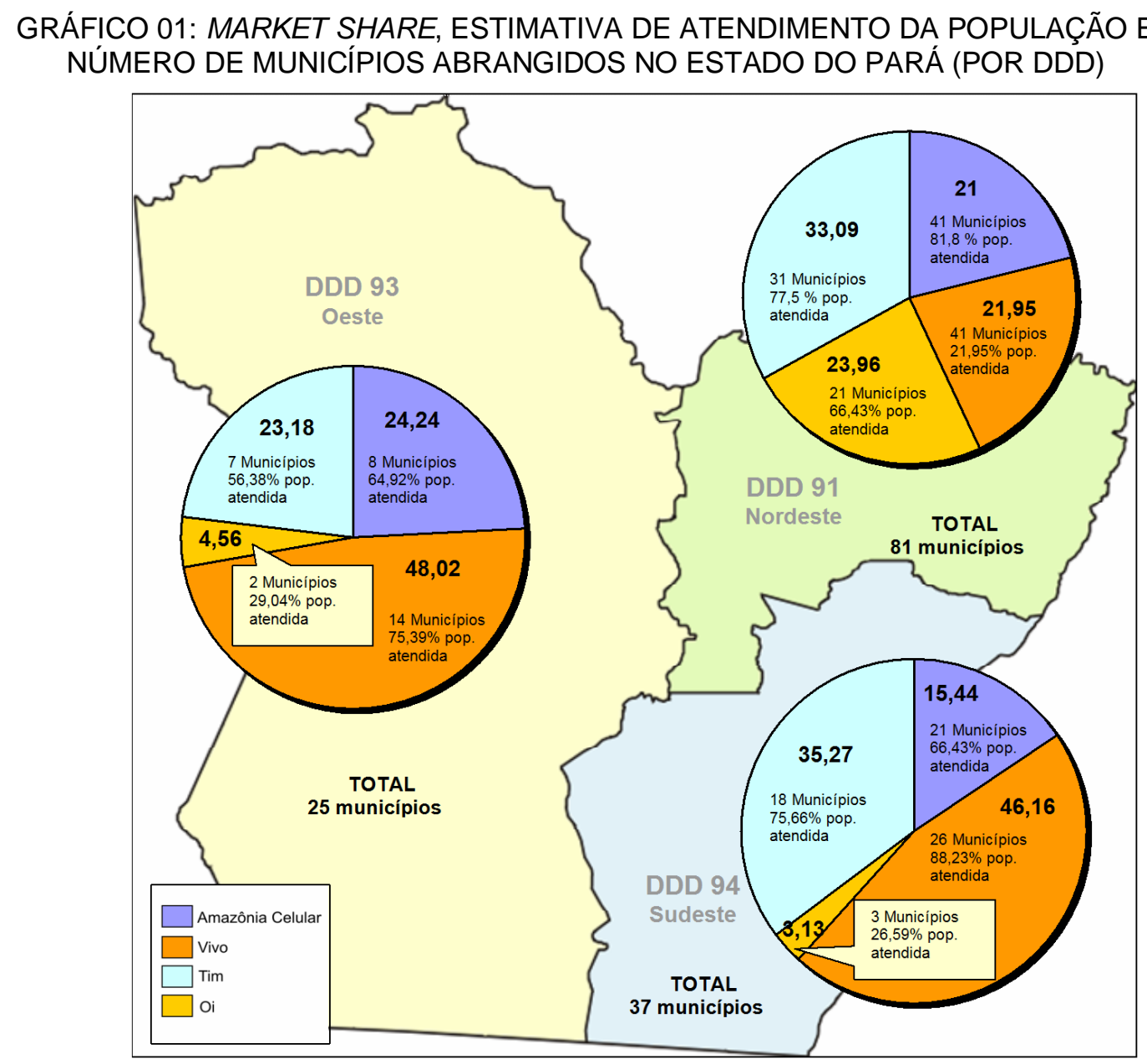

Fonte: Elaboração Própria com base em Teleco, 2007. 
Através do gráfico 01, é possível, também, visualizar algumas das estratégias das operadoras de telefonia móvel com relação aos nichos preferenciais de mercado através dos dados de Market Share, ou seja, as percentagens que representam a participação de cada companhia em determinados segmentos de mercado. O gráfico define, também, o número de municípios atendidos em cada uma das regiões e uma taxa de atendimento ao público (calculado em função da população dos municípios).

A Amazônia Celular preferiu, desde o início de sua expansão, uma estratégia bem mais difusa que as demais, buscando se estender pelo maior número possível de municípios, ampliando sua área de cobertura. Estima-se que esse fenômeno possa ter ocorrido por dois motivos: (i) pelo fato de a Amazônia Celular ter sido a primeira empresa privada a atuar no setor, buscou desde já ampliar sua capacidade de ação no território, visando adquirir maior confiabilidade do mercado e (ii) pelo fato de a disputa ainda não ter, efetivamente, se estabelecido, já que somente após a concessão das bandas D e E em 2002 que gigantes como Telecom Itália e Grupo Telemar começaram a ganhar parcelas significativas do mercado. A partir de então, a preocupação maior de todas as empresas era com as áreas mais rentáveis economicamente.

A VIVO, maior empresa do setor a atuar no território brasileiro, conseguiu superar, de longe, a concorrência que manteve durante os primeiros anos da concessão como a Amazônia Celular (nesta época a VIVO se chamava Norte Brasil Telecom - NBT). Se estendendo atualmente ao longo de 81 municípios do Pará, é também dominante no Oeste e no Sudeste paraense, tanto em rendimento quanto em atendimento à população. Apesar de a VIVO priorizar muitos municípios mais rentáveis no sudeste e oeste paraense (ver gráfico 01), ela foi superada pela TIM na área mais concentrada, o Nordeste paraense.

O padrão GSM, consolidado como a principal tecnologia de $2^{a}$ geração, fez com que empresas como TIM e Ol ascendessem rapidamente. O caso da TIM, oferecendo uma gama maior de produtos, serviços e promoções, fez com que sua presença fosse marcante nos principais centros urbanos. Sua estratégia pode ser visualizada como concentradora, uma vez que privilegiou Belém, Região Metropolitana e Nordeste Paraense como seus nichos preferenciais, dominando atualmente as parcelas mais significativas do mercado e superando todas as demais 
em rendimento. Porém, a TIM ainda se encontra entre as de menor atendimento à população no Pará (73,50\%), perdendo apenas para a OI (53,23\%).

A OI, como uma das mais novas operadoras de telefonia móvel a adentrar no território brasileiro, resolveu buscar mecanismos para atenuar os anos de atraso em relação às demais empresas. Por esse motivo suas ações se concentraram em Belém e região metropolitana (gráfico 01). Para se ter uma idéia, das 152 ERB's da empresa no Pará, 87 localizam-se em Belém (57,2\%) e 108 em toda região metropolitana (71\%), sendo que fora do nordeste paraense apenas 5 municípios são atendidos até 2007. Atualmente a empresa lança produtos e serviços mais acessíveis e promoções (principalmente no segmento pré-pago), visando atingir uma parcela maior da população. Com as estratégias de concentração, a empresa conseguiu ampliar significativamente sua capacidade de atuação no Nordeste paraense.

A partir da visualização dos dados no gráfico 01 e da análise proposta acima, podemos visualizar algumas das estratégias gerais das empresas de telefonia móvel no Estado do Pará no quadro 24, a seguir:

QUADRO 06: ESTRATÉGIAS GERAIS DAS EMPRESAS DE TELEFONIA MÓVEL NO ESTADO DO PARÁ

\begin{tabular}{|l|l|}
\hline Empresa & Estratégia \\
\hline Amazônia Celular & $\begin{array}{l}\text { Primeira empresa privada de telefonia móvel a atuar no Estado do Pará, } \\
\text { procurou se antecipar as demais e ampliar sua área de cobertura, atingindo } \\
\text { um maior número de municípios. Atualmente, busca competir com as } \\
\text { demais empresas no nordeste paraense e estender sua tecnologia GSM } \\
\text { Egde (ver quadro 07) a todos os municípios de sua área. }\end{array}$ \\
\hline Vivo & $\begin{array}{l}\text { Entrou no cenário paraense como retardatária da Amazônia Celular, por } \\
\text { isso procurou ampliar rapidamente sua área de cobertura e oferecer, mais } \\
\text { tarde, serviços digitais via tecnologia CDMA (ver quadro 05). Atualmente, } \\
\text { domina o mercado nas regiões sudeste e oeste paraense e supera as } \\
\text { demais empresas em área de cobertura. }\end{array}$ \\
\hline Tim & $\begin{array}{l}\text { Entrou no mercado em 2002 com a venda das banda D e E e massificou } \\
\text { seus investimentos na RMB. A Tim domina o mercado no nordeste } \\
\text { paraense e em todo o Pará, competindo fortemente nas demais regiões. } \\
\text { Contudo, é a que apresenta maior concentração se comparados seus } \\
\text { rendimentos com o número de municípios que atende. }\end{array}$ \\
\hline Oi & $\begin{array}{l}\text { É a principal retardatária na oferta de serviço de telefonia celular no estado } \\
\text { do Pará. Por esse motivo, preferiu concentrar seus investimentos da RMB. } \\
\text { Atualmente supera a vivo no nordeste paraense, mas no restante do } \\
\text { território sua participação é pouco significante frente às demais. }\end{array}$ \\
\hline
\end{tabular}

Fonte: Elaboração Própria. 
Para que as estratégias das empresas de telefonia móvel sejam mais bem reconhecidas, faremos uma espécie de zoneamento das áreas de interesse (mapa 01). Assim, será possível identificar agentes, definir relações e reconhecer os elementos que motivam as ações das empresas em determinadas lugares. Dessa forma, distinguiremos 5 áreas de estudos, são elas: a) polígono principal (RMB e adjacências); b) nordeste paraense; c) áreas de projetos econômicos; d) centros urbanos importantes e e) áreas rarefeitas. Concebemos que tais áreas sintetizam em si as lógicas privatistas das operadoras de telefonia móvel e, também, o caráter cooperativo dos agentes na utilização de determinados territórios para fins econômicos.

MAPA 02: MAPA INTEGRADO DA ÁREA DE COBERTURA DO SERVIÇO CELULAR NO ESTADO DO PARÁ - 2003

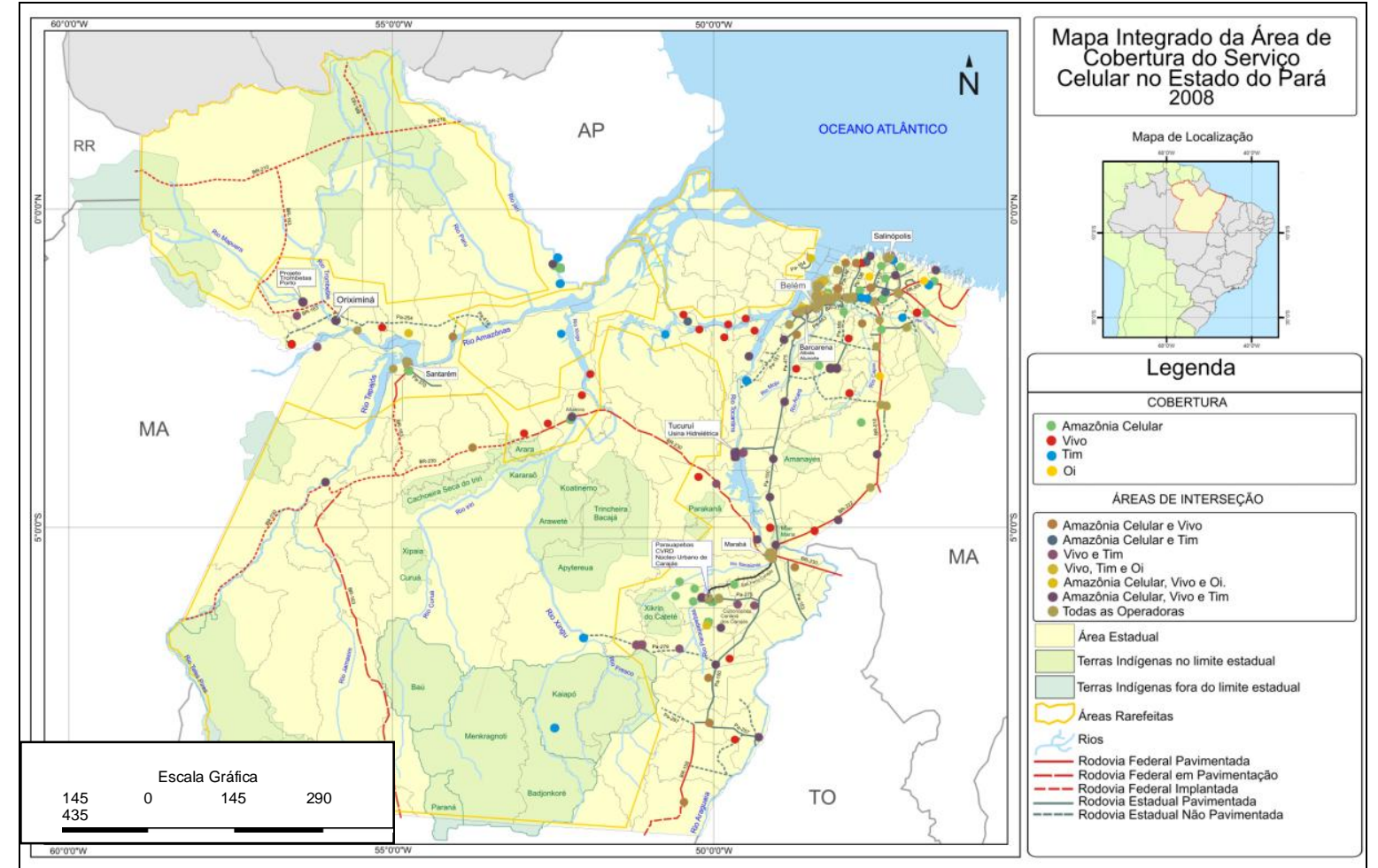

Fontes: Base Cartográfica Integrada Digital do Brasil ao Milionésimo. Rio de Janeiro. IBGE, 2003 (2) Cadastro de Estações Radiobase da Agência nacional de Telecomunicações (ANATEL), 2007. (3) Mapa Rodoviário do Pará, DNIT. 2002: (4) Mapa Regional de Terras Indígenas. SECTAN. Pa. 2005.

O polígono principal compreende a área que tem como núcleos centrais a RMB (Belém, Ananindeua, Marituba e Barcarena) e municípios adjacentes (Benevides e Santa Izabel) (ver mapa 02), representando $23 \%$ de toda população do Estado. Contudo, as características que permitem uma maior concentração nessa área 
dizem respeito, prioritariamente, a zona metropolitana ( $\mathrm{RMB})$. No polígono principal, há uma concentração significativamente maior de ERB's (359), o que significa 52\% das estações de todo Estado. De acordo com o georreferenciamento feito no mapa 02, foi possível observar que as empresas buscam as áreas centrais, tentando captar o maior número possível de localidades habitadas e, também, as áreas de fluxo intenso ao longo de vias expressas e rodovias de grande circulação. No polígono principal, as operadoras valorizam as áreas centrais da RMB, mas se instalam, também, em pontos bem específicos, como nas praias de Mosqueiro e Outeiro, que possuem cobertura exclusiva.

O nordeste paraense abrange algumas localidades ao longo das rodovias: BR316, BR-010, Pa-140, Pa-136 e Pa-127, destacando-se o município de Castanhal. Compreende, também, os municípios do litoral norte, como Maracanã, Curuçá, Salinópolis, Marapanim e Bragança, cobertos pelo serviço de telefonia celular (ver mapa 02). Dentre as áreas definidas no zoneamento, é a segunda mais concentrada, principalmente ao longo das $\mathrm{Br}-010$ e $\mathrm{Br}-316$, devido, principalmente, ao intenso fluxo regular de veículos e a presença de localidades de grande movimento econômico. Verificamos, nesse caso, a presença de fluxos de comunicação que servem a outros fluxos, como se observa no curso das rodovias federais. Essa estratégia é recorrente em outras zonas, mas não tão evidente quanto nesta, que se estende por mais de $100 \mathrm{~km}$ quase sem interrupção.

As áreas da telefonia celular onde se verifica a presença de projetos econômicos estão dispostas em vários pontos do território, com destaque à região de Carajás, no sudeste paraense, que constitui a área de maior vocação mineral na Amazônia e de maior fluxo de investimentos externos. Verificamos, nesses territórios, um direcionamento pontual da telefonia móvel, onde locais específicos são atendidos em favor de um grupo bem limitado de pessoas, a saber, técnicos e funcionários da CVRD. As firmas que aí se instalam são grandes empresas globais de lógicas extrovertidas, que atraem para si uma grande quantidade de fluxos e, pela sua presença marcante, exigem a afirmação impactante da modernidade. Os sistemas técnicos passam a ser instalados, então, de forma pontual, com prioridade para as áreas dos grandes projetos, em detrimento do resto do território. Nas áreas de projetos econômicos, os pontos de localização privilegiados são as vilas 
planejadas e as áreas de instalações dos projetos sob comando da CVRD, como ocorre em Barcarena (Vila dos Cabanos), Tucuruí (Vila Planejada) e Parauapebas (Núcleo Urbano de Carajás), todas com cobertura prioritária.

Os centros urbanos importantes se destacam pela dinâmica econômica intensa, principalmente Marabá, pela sua articulação com as cidades envolvidas no circuito da mineração, e Santarém, como pólo de articulação regional no oeste paraense, ambos privilegiados pelas empresas de telefonia.

As áreas rarefeitas cobrem vastas porções do território paraense, principalmente em espaços mais distantes das rodovias e próximas à malha fluvial. Nessas zonas, apenas algumas poucas localidades são atendidas, no máximo por duas operadoras em cada local. Nesse espaço, as empresas não obedecem a lógicas competitivas, não intensificam seus investimentos e, por conseguinte, não geram a qualidade e a eficiência presente nas demais zonas.

Diante dessas questões, podemos inferir que as conformações territoriais das empresas de telefonia móvel obedecem a critérios seletivos e pontuais. As empresas não apenas ponderam fatores técnicos para sua ação, mas, principalmente, fatores que dizem respeito ao desenvolvimento desigual e combinado do capitalismo, com áreas historicamente privilegiadas em oposição a zonas de fraco interesse.

Com base em nossa análise sobre os circuitos de poder e a territorialidade das empresas de telefonia móvel, foi possível observar que as firmas não se instalam em determinadas localidades obedecendo somente a critérios técnicos. Mas, sobretudo, decidem os melhores pontos de sua localização obedecendo a padrões territoriais historicamente definidos. Os "circuitos de poder", como definidos por Vieira e Vieira (2003) ocorrem, portanto, pela relação corporativa entre as empresas de telefonia e um conjunto de outros sujeitos dispostos em lugares específicos do território paraense. Por conseguinte, alguns lugares concentrados constituem verdadeiros círculos de solidariedades organizacionais, com agentes capazes de atrair para si fluxos de comunicação com grande intensidade. Em inúmeros outros pontos do território, as redes de telefonia móvel situam-se de forma compulsória, somente com obrigação de manter um mínimo de cobertura e de qualidade determinados pela ANATEL. 


\section{CONSIDERAÇÕES FINAIS}

A lógica de acumulação capitalista, marcada pela penetração das redes técnicas, sujeitou o estado do Pará à presença cada vez mais forte das fragmentações territoriais, tornando-o um campo de ação para novos conflitos, novas territorialidades que fazem deste uma das bases de operacionalização do "poder" na esfera global. Algumas dessas conformações territoriais obedecem uma lógica distante daquela visão tradicional de limite e enraizamento, mais se apresentam como organizações móveis e reticulares cujos pontos de operação podem ser ativados e desativados diante de nossos olhos, em fração de segundos. A materialidade das redes de telefonia móvel (sua feição técnica) não é monopólio de uma ou outra empresa, pois sua lógica é cooperativa, ou seja, permite que diferentes empresas utilizem o mesmo substrato material, mas com estratégias diferenciadas quanto ao "controle dos fluxos", que será a nova base da competitividade. Nesse aspecto, as estratégias viabilizadas pelas empresas de telefonia, em espacial das de telefonia móvel celular, vem constituindo um caso especial após a desagregação do padrão de financiamento público em 1998.

Antes da década de 70 o Pará era servido de algumas redes locais de telefonia que pouco influíam sobre o comportamento geral da sociedade e sobre as lógicas de acumulação de riquezas. Tratava-se de um privilégio de poucos agentes econômicos, em lugares restritos do território. A mudança definitiva vai se processar no território paraense a partir da mobilização dos agentes políticos sob o princípio da integração nacional, tão propalada pelo regime militar nas décadas de 60 e 70, produzindo uma difusão de redes interurbanas via satélite na Amazônia ao pé do modelo estatal, modernizador e desenvolvimentista. Vê-se, então, que o efeito da técnica não é de competência do artefato em si, mas está na ação social que o engendra, que faz deste um "instrumento" para o exercício do poder, conforme nos advertiu Raffestin (1993). Os agentes econômicos mais fortes são capazes de induzir demandas técnica através de uma mobilização mais ampla que pode incluir diversos segmentos sociais, gerando "surtos de solidariedade" para um projeto de 
cunho técnico, como a construção de uma hidroelétrica, de uma malha viária ou, no nosso caso, de uma rede de telecomunicações.

Os números da telefonia no Pará, antes da dec. de 70 , revelam um sistema fragmentado tanto no número de empresas em atuação quanto em suas formas de controle e gerenciamento. Foi somente com a criação da Telepará S.A (1972), subsidiária local da Telebrás S.A, que o sistema passou por um processo significativo de ampliação e modernização, principalmente após a criação de troncos de comunicação via satélite. Todo esse processo sofre, contudo, um grande abalo devido às mudanças de ordem política (fim do Governo Militar e redemocratização) e econômica (recessão e década perdida) ao final dos anos 80 e meados da década de 90. A partir de então, com os esforços do governo para uma abertura econômica ao mercado externo, permite-se a entrada de grandes empresas como Telefônica, Portugal Telecom e Telecom Itália no cenário nacional e regional.

Nesse momento, o território paraense adere ao contexto das redes técnicoinformacionais, globalmente conectadas. Essas redes são marcadas pela ampliação de infraestruturas modernas, de serviços de comunicação aprimorados e, também, pela penetração de empresas globais de lógicas extrovertidas, capazes de mobilizar um conjunto significativo de outros atores para viabilizar sua ação.

A privatização do território vai definir um novo modelo para difusão das redes em todo território nacional a partir de 1995, quando se inicia um primeiro conjunto de medidas no esforço de quebrar o monopólio das telecomunicações no Brasil, que tinha como símbolo maior a grande Holding Telebrás. Agora, com a atuação das grandes empresas globais de lógicas extrovertidas, o uso do território passa a ser corporativo, pautado sob a formulação de "alianças estratégicas", de "circuitos de poder", numa dialética entre a cooperação e o conflito, compartilhando metas, projetos e objetivos comuns, por um lado, e mantendo uma lógica de competitividade, de outro.

O sistema celular passa a evoluir, a partir de sua implantação na dec. de 90, de forma significativa, aumentando em mais de 500 vezes a sua abrangência quanto ao número de assinantes entre 1994 e 2007 (ANATEL, 2007). Em áreas cercadas pela malha fluvial, a telefonia celular constitui, particularmente, uma importante alternativa 
à telefonia fixa no tráfego de voz e dados, com grandes possibilidades de expansão nos próximos anos.

Os dados referentes à quantidade de ERB's por município, no Estado do Pará, em 2007, analisados na seção 3.2, revelam que, até 1997, a telefonia celular abrangia somente 3 municípios (Belém, Castanhal e Salinópolis). Isso se deve, por um lado, ao caráter experimental do serviço celular na época, que era extremamente caro e pouco atrativo para grande parte de população. Por outro lado, a telefonia no Brasil estava em processo de privatização e os investimentos eram aplicados com baixa intensidade em todo território brasileiro. A partir de 1998, com as entradas das operadoras nas bandas A (Amazônia Celular) e B (NBT, atual Vivo) é que o quadro da telefonia móvel passa a sofrer grandes alterações, com aumento significativo do número de usuários e localidades atendidas no Estado do Pará.

Com a consolidação do processo de privatização da telefonia móvel (através da concessão das bandas $\mathrm{D}$ e E), temos, no território paraense, a atuação de 4 empresas: duas começam a atuar em 1998, a Amazônia Celular e a VIVO (antes NBT). A Ol e a TIM entram a partir de 2002 e passam a disputar as parcelas do mercado mais favoráveis. A partir de 1998, os números de crescimento das comunicações móveis evoluem de forma exponencial, atingindo parcelas significativas da população. As tecnologias se aprimoram, os serviços ofertados aumentam, os preços caem e as possibilidades de uso multiplicam-se. No estado do Pará, de 1998 até 2007, 91 novos municípios receberam o sistema móvel.

As ERB's, pontos de acesso para a comunicação celular, constituem o dado fixo que revela a capacidade, a abrangência e, por conseguinte, a estratégia de atuação de cada empresa no território paraense. Por este motivo, o cadastro de ERB's da Anatel (2007) foi utilizado como principal fonte de dados para análise. No Pará, as estações se concentram no polígono principal, estacionado na RMB, onde todas as empresas mantêm um número significativo de antenas, em todos os casos, excedendo os $32 \%$ nessa área. Revelou-se, pela análise desses dados, que a VIVO é menos concentrada ${ }^{8}$ que as demais empresas (32,4\%), seguida da Amazônia Celular (47,7\%). A TIM (55,8\%) e a OI (72\%) são as mais concentradas,

\footnotetext{
${ }^{8}$ Refere-se à concentração de ERB's na RMB (Belém, Ananindeua, Marituba e Barcarena) em percentagem.
} 
principalmente esta última que, como vimos anteriormente, tenta recuperar o espaço perdido para as demais empresas. Esses dados revelam, a partir das definições de Santos (1998) que os lugares privilegiados pelas empresas são aqueles capazes de gerar lucros em curto prazo, onde as tecnologias são rapidamente absorvidas pela população de médio/alto poder aquisitivo.

O gráfico que mede o market share e o atendimento à população no Estado do Pará por regiões DDD revela que o nordeste paraense é o segmento territorial onde as empresas tentam equilibrar a disputa entre si. Empresas como a Ol chegam, inclusive, a se dedicar quase exclusivamente nessa área. Diante desse fato, questionamos o papel regulador da Anatel no que se refere à orientação dessas empresas e suas lógicas no Estado do Pará, visto que existe uma concentração significativa de estações em uma única área (com forte redundância) ao passo que 49 municípios do Estado (34,2\% do total) ainda não dispõem do serviço até 2007. Somente o município de Belém possui $40 \%$ de todas as antenas de radiofreqüência e o mesmo apresenta um contingente populacional de apenas $20 \%$ da população do Estado. Sabemos, contudo, que esse fenômeno diz respeito ao caráter capitalista dessas empresas, com o aumento da qualidade do serviço especialmente nos grandes centros, enquanto que o resto do território é atendido numa dinâmica mais lenta e numa qualidade inferior, apenas para seguir as metas de universalização da Anatel.

As diferentes territorialidades das instituições que estão ligadas aos serviços de telefonia no estado do Pará convivem e conflitam através da formulação de "circuitos de poder", ou seja, uma co-relação de forças que inclui o Estado (por intermédio da agencia reguladora - ANATEL) as empresas de telefonia fixa (pelo uso das mesmas bases materiais) e as empresas de telefonia móvel concorrentes (selecionando áreas comuns a compartilhando tecnologias). Tais agentes agem, concomitantemente, em caráter de cooperação e competitividade, porém, cada qual possui visões diferenciadas quanto as suas estratégias territoriais. A Agência reguladora, por exemplo, procura ver o território como um todo, já que representa ações estratégicas herdadas de um estado territorial, requerendo muito mais uma ação difusora que concentradora, a fim de justificar seu papel junto à sociedade. 
Diante das questões expostas acima, podemos inferir que as conformações territoriais das empresas de telefonia móvel obedecem a critérios seletivos e pontuais. As empresas não apenas ponderam fatores técnicos para sua ação, mas, principalmente, fatores que dizem respeito ao desenvolvimento desigual e combinado do capitalismo, com áreas historicamente privilegiadas em oposição a zonas de fraco interesse.

A ação territorial das empresas de telefonia no território paraense, segundo as definições teóricas de Haesbaert (2004), pode ser entendida pela formação de verdadeiros territórios-rede, em que o mais importante são as conexões entre os pontos de comunicação. Porém, as empresas, ao definirem suas redes, não desconsideram as zonas, que são utilizadas para estabelecer novas relações, traçar outras estratégias.

Esperamos que este trabalho seja, de fato, uma contribuição real aos estudos geográficos na Amazônia e no território paraense. Algumas informações que, porventura, não puderam ser aqui evidenciadas, podem ser traçadas em outras obras empreendidas por alunos, técnicos e pesquisadores, interessados em demonstrar a configuração do Estado do Pará enquanto apropriação social do território. Os agentes do sistema de telefonia definem, contudo, apenas uma malha desse emaranhado circuito técnico que, continuamente, se estabelece no território. Carecemos, no entanto, de uma gama enorme de estudos para explicar os processos que determinam essas redes, sua direção, velocidade e densidade. Há, ainda, um conjunto de malhas que não param de ser tecidas pelo movimento geral da sociedade, nesta, e em varias porções territoriais, em todo o mundo. 


\section{REFERÊNCIAS}

AGÊNCIA NACIONAL DE TELECOMUNICAÇÕES. Sistemas (on-line). Controle de Estações Rádio Base, 2007. Disponível:<http://www.anatel.gov.br/sistemas//> (Capturado em de 09 dez/2007).

BADIE, B. Le fin des territories. Paris: Fayard, 1995.

BECKER, B. A. Revisão das políticas de ocupação da Amazônia: é possível identificar modelos para projetar cenários? Parcerias Estratégicas - Número 12, 2001.

A. Geopolítica da Amazônia. Estudos Avançados n 19 (on-line). 2005. Disponível:<http://www.scielo.br/pdf/ea/v19n53/24081.pdf/>(Capturado em de 10/03/2008).

BRASIL. INSTITUTO BRASILEIRO DE GEOGRAFIA E ESTATÍSTICA (IBGE). Empresas Telefônicas - 1968. Rio de Janeiro, 1970.

. Empresas Telefônicas - 1972. Rio de Janeiro, 1976.

. Empresas Telefônicas - 1976. Rio de Janeiro, 1978.

DIAS, L. C. D. . Redes de telecomunicações e metrópole: ordem e desordem no papel hegemônico de São Paulo. In: VI Encontro Nacional da Anpur, 1996, Brasília. Anais do VI Encontro Nacional da Anpur. BRASÍLIA - DF: Cidade, 1995. v. 1. p. 1137-1143.

GALINA, S.V.R. Desenvolvimento Global de Produtos: o papel das subsidiárias brasileiras de fornecedores de equipamentos do setor de telecomunicações. São Paulo, 2003. Tese (Doutorado) - Escola Politécnica da USP.

HAESBAERT, R. O mito da desterritorialização: do fim dos territórios à multiterritorialidade. Rio de Janeiro: Bertrand Brasil, 2004.

MUSSO, P. Gênese et critique de la notion de reseau. In PARROCHIA, D. Penser les reseaux. Seussey: Champ Vallon, 2001. p.194-217.

RAFFESTIN, C. Por uma geografia do poder. São Paulo: Ática, 1993.

SANTOS, M. Por uma geografia das redes. In:

A natureza do espaço: técnica e tempo, razão e emoção. São Paulo: Hucitec, 1996. p. 208-222.

SANTOS, M. Técnica, Espaço e Tempo: globalização e meio técnico, científico, informacional. 4 ed. SP: Hucitec, 1998.

SHIMA. W. T. Strategic alliances' features and impacts on the competition of the switched telephony in brazil. Economia, Curitiba, v. 30, n. 1 (28), p. 7-30, jan./jun. 2004. Editora da UFPR.

TELECO (Home Page de Telecomunicações). Operadoras de Celulares. (online). Jan/2007. disponível:< http://www.teleco.com.br.>(Capiturado em 14 jan. 2007). 
VIEIRA, A. F e VIEIRA, M.M.F. Espaços econômicos: geoestratégia, poder e gestão do território. Porto Alegre: Editora Sagra Luzzatto, 2003.

(Recebido em outubro/2008. Aceito em julho/2009) 